\title{
The impact of the Covid-19 disruption on distance learning higher education students and activities
}

\author{
Maria Aristeidou, Simon Cross
}

Institute of Educational Technology, The Open University, UK.

\begin{abstract}
Higher education institutions are increasingly concerned about the impact of the disruption caused by the Covid-19 pandemic on students and learning activities. Yet, we know little about the effect of this disruption, specifically on students in distance learning higher education institutions. This study drew from survey responses of 555 undergraduate students at The Open University, UK. The aims of this study were to understand the impact of the Covid-19 disruption on learning, assessment and social activities that distance learning students commonly undertake and to explore how this impact relates to their background characteristics (socio-demographics and study properties). Findings showed that overall, students engaged in their study activities less frequently, with learning-related activities (e.g., joining live sessions) having the highest negative impact and social activities (e.g., accessing email for study purposes) the lowest. Female students were more likely than male to engage less across all three activity categories. Background characteristics, such as age, faculty and race, were associated with particular activity categories. This study is the first step towards enhancing our understanding of the engagement of distance learning, but also campus-based students in emergency distance learning, in online learning activities during the Covid-19 pandemic and other similar disruptions.
\end{abstract}

Keywords: Distance learning; higher education; online learning; Covid-19; student engagement. 


\section{Introduction}

The abrupt outbreak in January 2020 of the Covid-19 virus has created a crisis for many sectors, including the higher education (HE) sector. As a result, HE institutions (HEIs) have had to reconsider delivering effective learning using distance learning technologies following campus closures during the Covid-19 pandemic. Large-scale research involving 31,212 students in 62 countries (Aristovnik et al., 2020) indicates that switching from face-to-face to online teaching involved mainly delivering online lectures via real-time video conferences, but also asynchronous exchanges of resources between tutors-students and written communication via forums and chats. Sudden campus closures and lack of in-person support, led to students studying isolated at home in inappropriate learning environments while facing self-discipline issues (Bao, 2020). Moreover, this transition has resulted in students reporting increased workload and engaging more in completing assignments as a way to prove their participation in the course (Son et al., 2020). Further research reports that students' sociodemographics and study properties relate significantly to how they respond and experience this transition from face-to-face learning to online. For instance, female and art students reported to have a larger workload, and applied sciences and part-time students reported being less satisfied with their work-life balance (Aristovnik et al., 2020). Also, students from lower socioeconomic backgrounds reported experiencing stress about financial issues (Chirikov et al., 2020) and delayed graduations (Aucejo, 2020). Further, closures of schools affected households with school students resulting to higher demands on devices and internet access, and affecting parents' wellbeing (Garbe et al., 2020).

However, lockdown and shielding practices implemented by national governments have also affected students studying in distance learning HEIs. Motivated by the current lack of an empirical basis for insights into how the pandemic has impacted students and study activities in distance learning HEIs, we collected survey data from 555 students at The Open University (OU), during August-September 2020. The OU has been continuously developing its distance learning model since its foundation in 1969. The OU's supported open learning model includes delivering of courses via virtual learning environments, online tutorials and small tutor group forums, and evaluating student performance via tutor or computer marked summative or formative assessments. The OU also supports face-to-face exams and several other activities that were cancelled following the social distancing measures. Further, students at the OU are typically older than those of campus-based HEIs. To understand how the Covid-19 disruption has impacted the study activities at distance learning HEIs, we explored (a) the perceived change in time spent on learning, assessment and social activities that distance learning students commonly undertake during a course, and (b) how this perceived change relates to students' background characteristics, such as their gender, age, faculty, socioeconomic group, race and course start date. Our study extends previous research 
on how the Covid-19 pandemic affected HE students, and sheds light on the implications on distance learning students and activities.

\section{Methods}

\subsection{Development of 'study activities' list}

The initial list drew from a previous iterative survey with OU students' use of handheld technologies (Cross et al., 2019) and reflects actions that OU students usually undertake during a course. These items were aligned with Conole's (2013) learning activity categories and represent assimilative, communicative, information handling and productive activity domains. The initial list was reviewed and agreed with experts in the OU's (a) Quality Enhancement and Innovation team and (b) Design, Development and Production unit. The final list was reviewed and piloted with a large group of student volunteers $(n=201)$.

The study activities formed three self-report frequency scales designed to measure the students' self-perceived frequency change in undertaking certain learning activities: (a) the 7-item learning activity scale; (b) the 6-item assessment activity scale; and (c) the 4-item social activity scale. Likert scale responses ranged from 1 (much less frequently) to 5 (much more frequently). The score for each survey respondent equalled the mean score of the responses. Reliability analyses were carried out on the learning, assessment and social activity frequency scales. Cronbach's alpha showed the scales to reach acceptable reliability, with $\alpha=0.93$ for the learning activity scale, $\alpha=0.92$ for the assessment activity scale, and $\alpha$ $=0.85$ for the social activity scale.

\subsection{Data collection}

The survey was administered over two phases to students studying courses starting in October 2019 and February 2020. The students in the first phase were part of the Curriculum Design Panel, a group of students who frequently contribute their feedback to university matters, while students in the second phase were recruited via an invitation sent to a random university-wide sample. The survey ran between 29 July and 24 September 2020 and received 555 responses. Data collected include students' self-report on study activities, gender (female, male), age (25 and less, 25-34, 35-44, 45-54, 56 or over) and faculty (Social Sciences and Humanities/FASS; Science, Technology, Engineering and Maths/STEM; Education, Languages, Health and Sport Studies/WELS; Business and Law/FBL). Further information about background characteristics of phase 2 students $(n=354)$ was retrieved from the university database, such as their socioeconomic group (high/low), race (Black Asian or Minority Ethnicity/BAME or non-BAME) and course start (October 2019, February 2020). The dataset was anonymised on the 30th of September 2020, prior to initiating the process of data analysis. Ethical approval was obtained from the authors' university ethics committee. 


\subsection{Data analysis}

Descriptive statistics were used to describe the impact on the frequency by which $\mathrm{OU}$ students were undertaking particular learning, assessment and study activities, compared to their pre-pandemic study habits. Then, to determine how gender, age, faculty, socioeconomic group, race and course start relate to OU students' frequency of engaging in activities, independent-samples t-tests and analysis of variances (ANOVA) were performed. Scheffe post hoc tests confirmed flagged differences between groups detected by ANOVA. In the cases that Levene's F test revealed that homogeneity of variance assumption was not met, Games-Howell test was used. Descriptive statistics of the items used in the tests can be found in Table 1. An alpha level of .05 was used for all the analysis. Descriptive statistics reported in this study are means $(\mathrm{M}) \pm$ standard deviations (SD), unless otherwise noted.

Table 1. Descriptive statistics per study activity

\begin{tabular}{llll}
\hline $\begin{array}{l}\text { Background } \\
\text { characteristics }\end{array}$ & $\begin{array}{l}\text { Learning } \\
\mathbf{M} \pm \mathbf{S D}, \mathbf{n}\end{array}$ & $\begin{array}{l}\text { Assessment } \\
\mathbf{M} \pm \mathbf{S D}, \mathbf{n}\end{array}$ & $\begin{array}{l}\text { Social } \\
\mathbf{M} \pm \mathbf{S D}, \mathbf{n}\end{array}$ \\
\hline Gender & & & \\
$\quad$ Male & $2.75 \pm 0.82, \mathrm{n}=182$ & $2.79 \pm 0.74, \mathrm{n}=176$ & $2.83 \pm 0.74, \mathrm{n}=179$ \\
$\quad \begin{array}{l}\text { Female } \\
\text { Age }\end{array}$ & $2.43 \pm 0.86, \mathrm{n}=321$ & $2.59 \pm 0.78, \mathrm{n}=299$ & $2.69 \pm 0.85, \mathrm{n}=322$ \\
25 or less & $2.44 \pm 0.74, \mathrm{n}=64$ & $2.69 \pm 0.71, \mathrm{n}=63$ & $2.74 \pm 0.77, \mathrm{n}=64$ \\
$26-35$ & $2.42 \pm 0.89, \mathrm{n}=142$ & $2.59 \pm 0.80, \mathrm{n}=133$ & $2.77 \pm 0.86, \mathrm{n}=142$ \\
36-45 & $2.45 \pm 0.86, \mathrm{n}=122$ & $2.59 \pm 0.84, \mathrm{n}=112$ & $2.71 \pm 0.79, \mathrm{n}=123$ \\
$46-55$ & $2.57 \pm 0.89, \mathrm{n}=91$ & $2.63 \pm 0.72, \mathrm{n}=88$ & $2.58 \pm 0.85, \mathrm{n}=91$ \\
56 or over & $2.96 \pm 0.74, \mathrm{n}=85$ & $2.91 \pm 0.68, \mathrm{n}=80$ & $2.93 \pm 0.71, \mathrm{n}=82$ \\
Faculties & & & \\
WELS & $2.18 \pm 0.85, \mathrm{n}=73$ & $2.46 \pm 0.84, \mathrm{n}=63$ & $2.55 \pm 0.84, \mathrm{n}=72$ \\
STEM & $2.66 \pm 0.81, \mathrm{n}=146$ & $2.72 \pm 0.73, \mathrm{n}=142$ & $2.83 \pm 0.75, \mathrm{n}=148$ \\
FASS & $2.64 \pm 0.86, \mathrm{n}=201$ & $2.72 \pm 0.70, \mathrm{n}=187$ & $2.82 \pm 0.80, \mathrm{n}=199$ \\
FBL & $2.40 \pm 0.95, \mathrm{n}=56$ & $2.57 \pm 1.03, \mathrm{n}=54$ & $2.54 \pm 0.98, \mathrm{n}=55$ \\
Socioeconomic group & & & \\
High & $2.51 \pm 0.88, \mathrm{n}=280$ & $2.65 \pm 0.74, \mathrm{n}=253$ & $2.73 \pm 0.83, \mathrm{n}=278$ \\
Low & $2.67 \pm 1.02, \mathrm{n}=21$ & $2.67 \pm 1.02, \mathrm{n}=21$ & $2.90 \pm 0.90, \mathrm{n}=22$ \\
Course start & & & \\
October 2019 & $2.51 \pm 0.88, \mathrm{n}=259$ & $2.64 \pm 0.77, \mathrm{n}=230$ & $2.75 \pm 0.81, \mathrm{n}=254$ \\
February 2020 & $2.62 \pm 0.95, \mathrm{n}=58$ & $2.70 \pm 0.72, \mathrm{n}=61$ & $2.80 \pm 0.93, \mathrm{n}=62$ \\
BAME & & & \\
Yes & $2.54 \pm 0.89, \mathrm{n}=297$ & $2.67 \pm 0.76, \mathrm{n}=276$ & $2.78 \pm 0.84, \mathrm{n}=298$ \\
No & $2.31 \pm 0.91, \mathrm{n}=18$ & $2.33 \pm 0.77, \mathrm{n}=13$ & $2.31 \pm 0.69, \mathrm{n}=16$ \\
\hline
\end{tabular}




\section{Results}

The data $(N=555)$ show the students' perceived change in time spent on certain activities. Overall, OU students reported engaging in their study activities less frequently or without change with an average score of 2.63, on a range of 1 (much less frequently) to 5 (much more frequently). Learning activities had the highest negative impact with students reporting less frequent engagement $(2.56 \pm 0.86)$ while social activities had the lowest negative impact with students reporting no change or less frequent engagement $(2.75 \pm 0.81)$.

\subsection{Learning activities}

The following table (Table 2) shows students' usual learning activities in order of negative impact on time spent on the activity, compared to pre-pandemic. Joining synchronous online tutorial sessions was the most negatively impacted learning activity, scoring closer to 'less frequently'. Other items with high negative impact, involve non-mandatory activities, such as reading non-OU learning material or search for academic report/papers. Finding information on the internet (an activity of low granularity) was the least negatively impacted, scoring closer to 'no change'. Survey respondents, overall, reported that they engaged in learning activities less frequently than before or without any change.

Table 2. Descriptive statistics for learning activity frequency, in order of negative impact. Ranged from 1 (much less frequently) to 5 (much more frequently).

\begin{tabular}{lcc}
\hline Learning activities & n & M \pm SD \\
\hline Joining Live OU sessions & 538 & $2.41 \pm 1.08$ \\
Reading non-OU learning materials related to your OU studies & 544 & $2.49 \pm 1.08$ \\
Searching for academic reports or papers & 530 & $2.50 \pm 0.97$ \\
Watching or listening to OU learning materials & 548 & $2.58 \pm 0.96$ \\
Writing or taking notes & 551 & $2.63 \pm 0.98$ \\
Reading OU learning materials & 552 & $2.64 \pm 1.02$ \\
Finding information on the internet & 546 & $2.74 \pm 1.02$ \\
Average of all learning activities & 516 & $2.56 \pm 0.86$ \\
\hline
\end{tabular}

Findings from examining the relationships among frequency of engaging with learning activities and background characteristics of OU students show that female students were engaging less frequently than male $(t[501]=4.08, p<.001)$; students aged 56 or over were engaging more frequently than students of other age groups $(F[4,499]=6.54, p<.001)$; and students in WELS were engaging less than students in STEM and FASS $(F[3,472]=6.74$, $p<0.001)$. There were no significant differences between students of high and low socioeconomic group $(t[299]=0.08, p=0.45)$; BAME and non-BAME students $(t[313]=1.06$, $p=0.29)$; nor students starting in October 2019 and February $2020(t[315]=0.85, p=0.39)$. 


\subsection{Assessment activities}

Table 3 shows students' usual assessment-related activities in order of negative impact. Revision was the most negatively impacted activity, scoring closer to 'less frequently', followed by practice quizzes and preparing an assignment. Accessing TMA scores (an activity of low granularity) was the least negatively impacted. Likewise, downloading marked TMAs was impacted less. Similarly to the feedback on learning activities, survey respondents reported that they engaged in assessment activities overall less frequently than before or without any change.

Table 3. Descriptive statistics for assessment activity frequency, in order of negative impact. Ranged from 1 (much less frequently) to 5 (much more frequently).

\begin{tabular}{lcc}
\hline Assessment activities & $\mathbf{n}$ & $\mathbf{M} \pm \mathbf{S D}$ \\
\hline Revision & 523 & $2.47 \pm 1.04$ \\
Practice quizzes & 510 & $2.51 \pm 0.95$ \\
Preparing an assignment (TMA) & 547 & $2.61 \pm 1.02$ \\
Acting on feedback from tutors & 546 & $2.76 \pm 0.86$ \\
Downloading your marked TMAs & 545 & $2.78 \pm 0.78$ \\
Accessing TMA scores & 547 & $2.86 \pm 0.83$ \\
Average of all assessment activities & 488 & $2.66 \pm 0.77$ \\
\hline
\end{tabular}

Findings from examining the relationships among frequency of engaging with assessment activities and background characteristics of OU students show that female students were engaging less frequently than male $(t[473]=2.75, p=.006)$ and students aged 56 or over were engaging more frequently than students aged $26-35$ and $36-45(F[4,471]=2.78, p=0.03)$. There were no significant differences between students in different faculties $(F[3,442]=2.35$, $p=0.07)$; students of high and low socioeconomic group $(t[21.79]=0.05, p=0.96)$; BAME and non-BAME students $(t[287]=1.55, p=0.12)$; and students in courses starting in October 2019 and February $2020(t[289]=0.51, p=0.61)$.

\subsection{Social activities}

The following table (Table 4) shows students' usual social activities in order of negative impact. Social media for study purposes was the most negatively impacted activity, scoring closer to 'less frequently', while social media for socialising was the item with the lowest negative impact, with survey respondents reporting an overall 'no change' to this habit. Feedback on social activities indicates an overall less negative impact, compared to learning and assessment activities. 
Table 4. Descriptive statistics for social activity frequency, in order of negative impact. Ranged from 1 (much less frequently) to 5 (much more frequently).

\begin{tabular}{lcc}
\hline Social activities & $\mathbf{n}$ & $\mathbf{M} \pm \mathbf{S D}$ \\
\hline Social media for study purposes & 520 & $2.65 \pm 0.97$ \\
Accessing OU forums & 548 & $2.66 \pm 1.02$ \\
Accessing email for study purposes & 550 & $2.76 \pm 0.87$ \\
Social media for socialising & 524 & $2.95 \pm 1.16$ \\
Average of all social activities & 514 & $2.75 \pm 0.81$ \\
\hline
\end{tabular}

Findings from examining the relationships among frequency of engaging with social activities and background characteristics of OU students show that female students were engaging less frequently than male $(t[410.14]=1.99, p=0.048)$ and BAME studentsless frequently than non-BAME $(t[312]=2.18, p=0.03)$. There were no significant differences between students of different age $(F[3,497]=2.12, p=0.08)$; faculties $(F[3,470]=2.40$, $p=0.052)$; high and low socioeconomic group $(t[298]=0.90, p=0.37)$; and students in courses starting in October 2019 and February $2020(t[314]=0.43, p=0.67)$.

\section{Discussion}

Overall, a negative impact on the frequency of undertaking study activities was reported across all three activity categories. The time spent on learning activities was highly negatively impacted by the Covid-19 pandemic, with students engaging less frequently with the equivalent activities, while social activities had the lowest. The most affected study items were joining Live OU sessions (Table 2) followed by revision (Table 3). Routine disruption, because of employment issues and childcare or other caring responsibilities that characterise older students (e.g., Garbe et al., 2020), could explain a perceived negative change in the frequency by which students were joining Live OU sessions (which is a synchronous event) or undertaking learning activities overall. Further, the OU's decision to cancel face-to-face final exams may explain why students reported negative impacts on time spent revising. This finding also contradicts studies (e.g., Son et al., 2020) reporting students of campus-based HEIs having an increased engagement with assignments to prove their participation.

With respect to how this perceived change in time spent on certain activities relates to students' background characteristics, the findings of this study show that female students reported engaging less with their study activities than male. This finding is consistent with gender-related studies in campus-based HEIs (e.g., Aristovnik et al., 2020), and it may be explained due to life expectations and changes in personal circumstances during Covid-19. Covid-19 personal circumstances (for example, self-isolation) may have also allowed more time for students aged 56 or over to engage in learning and assessment activities. WELS 
students were engaging less frequently in learning activities than STEM and FASS students, perhaps because WELS involves students in activities, such as face-to-face visits at hospitals (nursing) or schools (education). BAME students were engaging less frequently in social activities than non-BAME students. This finding needs further investigation, and it can form a vital issue for future research. Regarding socioeconomic background, contrary to research on campus-based HEIs (e.g., Chirikov et al., 2020), there were no significant differences between students in high and low socioeconomic groups. Finally, no significant differences were found between students starting in October 2019 and February 2020, although the former had short notice about changes to assessment.

Our findings add to a growing body of literature on how distance learning, and also campusbased students in emergency distance learning, engage in particular study activities online during disruptions. An essential next step will be to scope and explore new opportunities for teaching and learning with practices that respond to broader social and economic change. Maintaining engagement during disruptions could be achieved by adopting inclusive programme designs and providing alternative activitiy types and modes.

\section{References}

Aristovnik, A., Keržič, D., Ravšelj, D., Tomaževič, N., \& Umek, L. (2020). Impacts of the COVID-19 pandemic on life of higher education students: A global perspective. Sustainability, 12(20), 8438. doi: 10.3390/su12208438

Aucejo, E. M., French, J., Ugalde Araya, M. P., \& Zafar, B. (2020). The impact of COVID19 on student experiences and expectations: evidence from a survey. Journal of Public Economics, 191, 104271. doi: 10.1016/j.jpubeco.2020.104271

Bao, W. (2020). COVID-19 and online teaching in higher education: a case study of Peking University. Human Behavior and Emerging Technologies, 2(2), 113-115. doi: $10.1002 /$ hbe 2.191

Chirikov, I., Soria, K. M., Horgos, B., \& Org, E. (2020). Undergraduate and graduate students' mental health during the COVID-19 pandemic. Centre for Studies in Higher Education. Retrieved from https://escholarship.org/uc/item/80k5d5hw

Conole, G. (2013). Designing for Learning in an Open World. Springer: Verlag New York.

Cross, S., Sharples, M., Healing, G., \& Ellis, J. (2019). Distance learners' use of handheld technologies: mobile learning activity, changing study habits, and the "place" of anywhere learning. International Review of Research in Open and Distance Learning, 20(2), 223-241. doi: 10.19173/irrodl.v20i2.4040

Garbe, A., ogurlu, U., Logan, N., \& Cook, P. (2020). Parents' experiences with remote education during COVID-19 school closures. American Journal of Qualitative Research, 4(3), 45-65. doi: 10.29333/ajqr/8471

Son, C., Hegde, S., Smith, A., Wang, X., \& Sasangohar, F. (2020). Effects of COVID-19 on college students' mental health in the United States: interview survey study. Journal of Medical Internet Research, 22(9), e21279. doi: 10.2196/21279 